\title{
APLICAÇÃO DE UMA PESQUISA DE USABILIDADE PARA \\ REESTRUTURAÇÃO DO LAYOUT DA PÁGINA WEB INFOHAB.
}

\section{THE USE OF USABILITY RESEARCH FOR THE DEVELOPMENT OF RESTRUCTURING THE INFOHAB REFERENCE CENTER LAYOUT.}

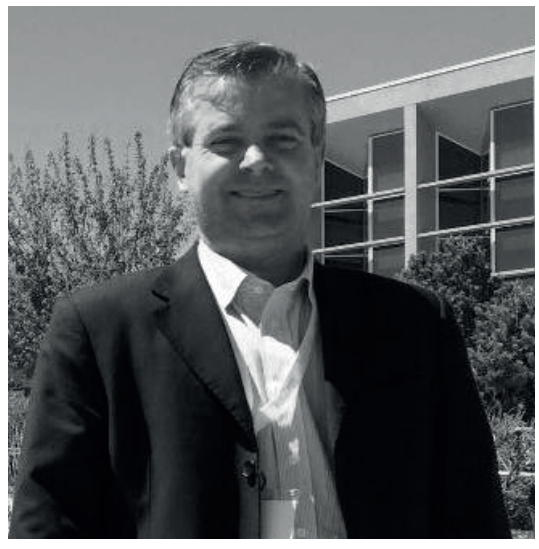

\section{Claudio Alcides Jacoski}

Professor do Programa de Pós-Graduação em Tecnologia e Gestão da Inovação e do Programa de Pós Graduação em Contabilidade e Administração da Unochapecó. Doutor em Engenharia de Produção - Universidade Federal de Santa Catarina, claudio@unochapeco.edu.br

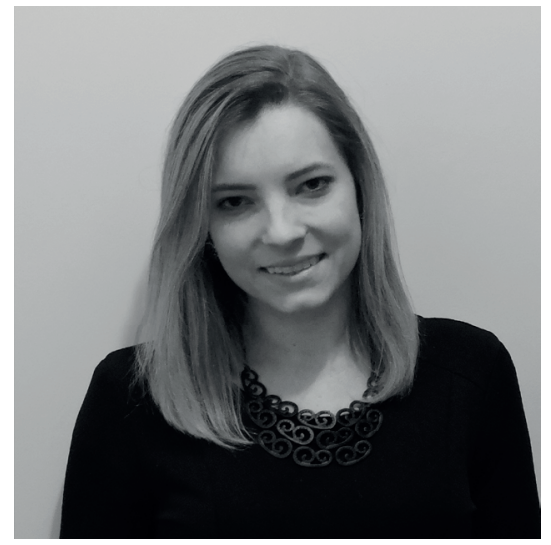

\section{Caroline Dallacorte}

Mestranda em Tecnologia e Gestão da Inovação Universidade Comunitária da Região de Chapecó, Graduada em Engenharia de Alimentos pela Universidade Comunitária da Região de Chapecó - Unochapecó carold@unochapeco.edu.br 


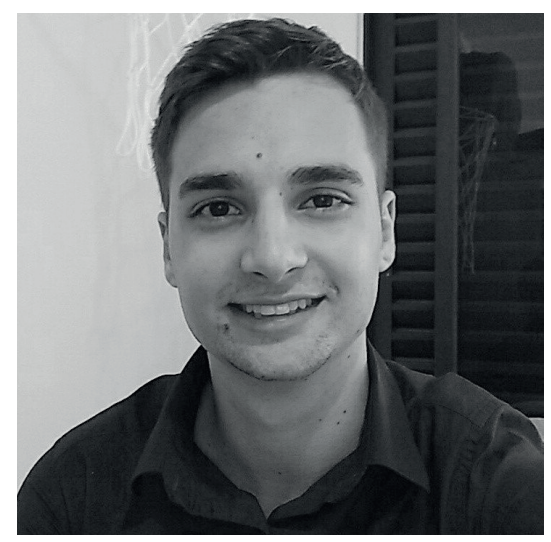

\section{Antônio Eduardo Rech Mota}

Bolsista PIBIC - Unochapecó

Graduando de Publicidade e Propaganda - Universidade

Comunitária da Região de Chapecó

antoniomota@unochapeco.edu.br

\section{RESUMO}

A pesquisa de usabilidade tem o intuito de avaliar os pontos positivos e negativos de uma página web, evidenciando melhorias. Neste trabalho, profissionais e acadêmicos da área realizaram a pesquisa, através da sua experiência na página do infoHab, contribuindo para o ajuste de falhas e destaque de pontos essenciais do site. Com isso, foi possível realizar a modernização da página, meIhorar mecanismos do sistema, utilizar a psicodinâmica das cores e aprimorar em geral a funcionalidade e a identificação das ferramentas.

\section{PALAVRAS-CHAVE}

InfoHab; Pesquisa de Usabilidade; Layout.

\section{ABSTRACT}

Usability research aims to assess the positives and negatives of a web page, showing improvements. In this work, professionals and scholars in the field carried out the research, through its experience in InfoHab page, contributing to the failure of adjustment and highlight key points of the site. Thus, it was possible to carry out the modernization of the page, improve system mechanisms, use the psychodynamics of colors and enhance overall functionality and identification of tools.

\section{KEYWORDS}

InfoHab; Usability Research; Layout. 


\section{INTRODUÇÃO}

Este artigo tem como finalidade descrever os processos de planejamento e metodologias utilizados para a reestruturação do Centro de Referência InfoHab com a evolução da Web 1.0 para a Web 2.0 melhorando os pontos negativos de interatividade do site descobertos através de uma pesquisa de usabilidade. O Centro de Referência e Informação em Habitação - InfoHab, é um projeto o qual tem como líder a Associação Nacional de Tecnologia do Ambiente Construído - ANTAC, com o intuito de aperfeiçoar as técnicas de organização sistemática e compartilhada de informação na área de ambiente construído, o qual passou por um processo de reestruturação guiado pela Unochapecó para a modernização estrutural para melhor eficiência em seus objetivos.

A usabilidade refere-se à qualidade e a facilidade de uso que o sistema pode proporcionar ao indivíduo. Torna mais simples a interatividade, para que os objetivos do usuário sejam alcançados de uma forma mais rápida e eficaz, e as funcionalidades das ferramentas tenham uma forma mais ágil de aprendizado no comportamento, fazendo com que o indivíduo não passe muito tempo perdido no site procurando seus objetivos. A pesquisa de usabilidade, tem o objetivo de medir o processo de experiência do usuário no site, apontando resultados nas áreas que contém falhas de interatividade, e as áreas de forte funcionalidade para gerar resultado que é utilizado como base no planejamento de reestruturação da página. A internet chegou a evolução do 2.0, a qual saiu do formato antiquado dos anos 90 (na era 1.0) para uma reestruturação a qual consegue passar uma sensação de interatividade com o consumidor mais forte. Esse processo ganha força e aumenta seus resultados positivos, pois na sua criação, reúne profissionais de diferentes áreas, por exemplo, computação, design, publicidade, psicologia, linguística, fazendo com que o conteúdo da página possibilite ao internauta uma navegação mais confortável e eficaz.

A constante proximidade do consumidor, deixa mais fácil a percepção de uma mudança na rede da web. Pesquisas de usabilidade tem grande percentual de competência para saber onde o site está acertando e errando, para que possa fazer um planejamento de mudança para melhorar a qualidade de serviço. $\mathrm{O}$ imediatismo é um problema, o trabalho individual ou uma escolha sem planejamento, pode acarretar em uma série de problemas, o estudo e o conhecimento de vários profissionais, são peças chaves para que a qualidade que o site necessita seja alcançado.

Os objetivos analisados são a modernização da página, melhorar o sistema de busca, utilizar a psicodinâmica das cores, melhorar em geral a funcionalidade e 
a identificação das ferramentas e melhorar a divulgação das páginas e a aproximação com os usuários através de redes sociais. A metodologia para a busca dos objetivos foi a pesquisa de usabilidade feita com os usuários do InfoHab, estudo e planejamento de ações para melhorar a interatividade, escolha e formação de profissionais de várias áreas gerando qualidade de serviço.

\section{REVISÃO BIBLIOGRÁFICA}

\subsection{EXPERIÊNCIA DO USUÁRIO NA WEB}

Os portais na internet atualmente, tem um desafio de conquistar a permanência e a fidelidade do internauta na sua rede, onde possuem aproximadamente dois minutos para se comunicar com o usuário, caso isso não aconteça o indivíduo passa a procurar outro site. O proprietário do site precisa deixar claro os caminhos para os objetivos dentro do site, para que o usuário tenha melhor interatividade e efetividade na busca sem precisar quebra a cabeça para encontrar o que está procurando.

As experiências dos usuários vão se aperfeiçoando com o tempo, portanto as pessoas que utilizam essa tecnologia a mais tempo, já tem um comportamento automatizado para sites favoritos e ferramentas de buscas, por isso é essencial que os proprietários de uma rede deixem claro "O que é?", "Como funciona”, "Para que?" o site funciona, agradando assim o público que vai guardá-lo em sua memória, gerando uma satisfação entre vários fatores, voltando sempre que necessário a busca de conteúdo ofertado.

"Só é lembrado quem é visto", nas ferramentas de pesquisas (Google, Bing) os sites que aparecem nas primeiras opções de resultados, são os que os usuários tem maior preferência e confiança de acesso, somando com uma identidade visual cativante e caminhos rápidos em sua navegação, resultam em uma experiência positiva no internauta, mas também os usuários passaram a não procurar mais por um serviço e sim serem procurados, através de suas redes sociais, ou anúncios em sites de alta frequência, assim o proprietário tem que utilizar essas ferramentas para atrair o seu público se ele quiser obter sucesso

\subsection{WEB 1.0 E 2.0}

O proprietário do site, pode perceber que passa por algum problema na interatividade quando precisa sinalizar ao usuário onde ele deve clicar, como ele deve rolar a página, leva-lo ao um labirinto de cliques até chegar ao local desejado. Com a evolução da internet 1.0 para a 2.0 as páginas deixaram de ser algo com links cheios 
de cores e gifs animados como letreiros para guiar o internauta dentro do site, os atalhos passaram a ser representados por pictogramas o site ficou com um visual mais flat e clean, a objetividade nos resultados foi reduzida ao máximo de cliques. A internet 2.0 possibilita a melhor oferta de um produto (Site) em conteúdos multimidáticos, a expansão por meios de redes sociais, potencializando a troca de informações, utilizando ferramentas mais interativas na experiência tecnológica do usuário. Também abre portas para que muitas operações realizadas antes off-line, pudessem ser praticadas online, através de programas e recursos tanto gratuitos quanto pagos, que antes não eram disponibilizados por falta de tecnologia suficiente para execução.

A coletividade é uma das essências da web 2.0, onde passou a possibilitar a que qualquer usuário seja um criador de opinião, onde possa colocar informações online, editar e propagar/compartilhar dentro da rede alcançando uma grande massa de internautas, criando assim uma inteligência coletiva.

\subsection{PESQUISA DE USABILIDADE}

Com o passar do tempo, os internautas aprenderam a utilizar a internet e suas ferramentas, evoluíram a percepção de como interagir na web, isso fez com que a metodologia da usabilidade fosse mais eficaz, pois o usuário sabe exatamente a onde está o problema e como pode ser resolvido, assim apontando claramente os resultados em uma pesquisa de usabilidade.

"A usabilidade pode ser uma questão de vida ou morte. Na guerra, um soldado em um bombardeiro tem uma boa vantagem se a interface com o usuário de seu avião para os sistemas de mira e disparo for apenas um segundo mais rápido que os do seu inimigo. Na Web, naturalmente, a usabilidade não tem um papel tão crucial. Mas isso pode determinar se seu Website é bem ou malsucedido." (LORANGER, 2007, p.123)

Com base na teoria de Lipovetsky, a sociedade está vivendo em uma fase hipermoderna, onde o indivíduo está querendo fazer tudo ao mesmo tempo, quer consumir conteúdo de várias mídias juntas, tem uma movimentação maior entre os assuntos, não quer mais perder seu tempo em apenas um lugar. A usabilidade em um site propõe para o usuário maneira rápida de consumo, como buscas avançadas, melhor organização, utilidade em cores para funções de ferramentas. A pesquisa de usabilidade teve como principal fundamento identificar as ferramentas presentes no InfoHab que estavam causando desconforto no momento de navegação do usuário, arquivando resultados quantitativos nas questões objetivas e qualitativas nas opções que eram abertas para sugestões para que 
pudessem serem resolvidos de uma forma eficaz e resolver se não todos, a grande maioria de problemas que o acervo tinha em sua estruturação.

\subsection{DESIGN PARA PÁGINA WEB}

Menos é mais, pode-se resumir assim a maneira mais eficiente para um webdesign, as formas mais simples, mais limpas, são as que são mais efetivas, desde a sua URL sendo nomeada de forma lógica e simples até a sua diagramação, opção de cores para ser recordado, o design pesado faz com que se desvie a atenção de alguns pontos importantes que podem ser relevantes.

Como cita Anielle Damasceno (2003, p. 11) "Assim como a cor simboliza emoções, a forma representa muito mais que isso. A forma é o meio mais abrangente para representar a função de determinado elemento.". Analisando, foi posto em prática para resolver problemas de proporção de layout, visibilidade e destaque utilizando pictogramas para representar ações como "leia mais", "clique aqui", "atenção" melhorando a interatividade do site, substituindo por símbolos os quais os usuários já estão educados simbolicamente na web, como por exemplo setas para baixo indicando mais informações ocultas, setas para a direita com o objetivo de indicar para prosseguir, ponto de exclamação destacado demonstrando atenção, links e buscas de cores diferentes para que seja notório em meio ao texto e para que sejam encontrados com maior facilidade em um rápido acesso ao site.

A coerência visual trata-se de uma harmonização entre todos os aspectos presentes, que todos os elementos se completem e tornem um mesmo conceito visual. Deve ser tratado como um ambiente físico, como por exemplo o próprio lar, o tapete combina com o sofá que combina com o papel de parede e assim sucessivamente, todos esses elementos juntos se completam e formam o conceito visual da casa, passando sensações agradáveis e não brigam entre sí, no website os elementos de tipografia, linhas, cores, pictogramas, devem interagir como se fossem um só. Mas isso não impede que um elemento cause um desconforto visual ao internauta, mas só é funcional quando ele tem um objetivo de causar esse impacto, como afirma Damasceno (2003, p. 10), "É importante não confundir desarmonia com destaque intencional. O Webdesigner tem toda a liberdade de criar novos estilos e enfatizar elementos da melhor forma que puder, e isso é o diferencial do bom profissional.".

Não adianta o site ser fácil de mexer, estar cheio de conteúdos relevantes, se a identidade visual dele não é agradável, se a diagramação das informações não estarem estruturadas de fácil leitura, o usuário só vai gostar do site se a interfa- 
ce agradar ele e favorecer a continuar sua busca de conteúdo, pois somente as informações não conquistam um internauta.

\subsection{CENTROS DE REFERÊNCIA EINFORMAÇÃO (BIBLIOTECAS DIGITAIS)}

Os centros de referência e informação são por muitas vezes desconhecidos por serem apresentados com outras denominações, como por exemplo bibliotecas digitais ou virtuais. De acordo com Assunção (2011), podem ser definidos de diversas formas, porém, nenhuma definição se compreende por completo. Todos estes sinônimos citados possuem características muito semelhantes uma vez que o objetivo é repassar informações de forma eletrônica para a comunidade acadêmica, seja professores, acadêmicos, empresas ou qualquer entidade relacionada a pesquisa e que tenha interesse em obter materiais para leitura e conhecimento. Além disso, este repasse é feito de forma prática e na maioria das vezes, de forma gratuita, auxiliando na disseminação de informação.

O número de centros de referência e bibliotecas digitais aumentou consideravelmente nos últimos tempos visto que o surgimento de programas gratuitos para a construção de repositórios contribui para o desenvolvimento deste tipo de transmissor de conhecimento (DE MOURA, 2015). É importante ressaltar que os centros de referência possuem algumas vantagens uma vez que sua base de dados lida também com serviços que servem de apoio a todas as etapas da geração de conhecimento. Serve também para a inclusão de fóruns que geram discussão entre pesquisadores, divulgação de chamadas de trabalhos e realização de eventos, além de trabalharem na gestão de processo de avaliação de eventos e periódicos, contribuindo com novas pesquisas e diálogo entre os usuários.

\section{METODOLOGIA}

Para dar início ao estudo, buscou-se conhecer a página do infoHab e identificar primeiramente quais os principais pontos a serem modificados no layout. A partir disto, desenvolveu-se uma pesquisa de usabilidade, composta por 19 questões, múltipla-escolha e descritivas, que foi aplicada em uma turma do $9^{\circ}$ período do curso de Engenharia Civil da Unochapecó. Participaram desta atividade 36 pessoas, dentre elas acadêmicos, professores e profissionais da área. A pesquisa foi realizada em duas etapas, onde inicialmente enviou-se um e-mail aos entrevistados solicitando que os mesmos navegassem na página do infoHab, a fim de que houvesse uma interação e melhores resultados nas respostas. O próximo passo consistiu na aplicação da pesquisa de usabilidade, recebendo ao final sugestões valiosas para a melhoria do site. Os principais pro- 
blemas relatados pelos usuários entrevistados foram:

- Dificuldade na visibilidade da tela de cadastro/login;

- Proporção inadequada de layout;

- Aprimorar busca avançada, adicionando novos filtros: datas e índices de download;

- Possibilidade de diferenciar cores nos resultados para melhor visualização;

- Tipografia do menu principal desapropriada;

- Falta de destaque dos links;

- Melhorias na divulgação da página para tornar conhecida, utilizando recursos como redes sociais.

A partir destas sugestões, iniciou-se a um planejamento de equipe e de ação para a melhoria dos fatores apontados, buscando solucionar os problemas encontrados na página e adicionar novas funcionalidades a fim de tornar o site uma ferramenta ainda mais útil para todos os usuários.

No desenvolvimento do novo layout do InfoHab, foram utilizados os programas Illustrator para produção da interface e Photoshop para manipulação de imagens que estão inseridas dentro do acervo. Para o redesign o processo criativo iniciou com a análise dos pontos que foram resultados da pesquisa de usabilidade, com isso gerou um campo semântico para pesquisa de referências visuais e interativas, passando então a criação de uma identidade conceito para a produção das páginas do InfoHab. Após este processo, foram feitas avaliações e alterações pela equipe refinando o projeto até que estivesse respondendo a todas as mudanças propostas. A escolha das cores teve um objetivo cromático em transmitir sensações que confortassem o usuário, a cor azul transmite sentimento profundo, confiança, serenidade, fluidez e admiração, a cor vermelha contrasta com o azul destacando as ferramentas e também transmite conquista, força, paixão e é estimulante.

Com relação aos problemas de proporção de layout, visibilidade e destaque, utilizou-se pictogramas para representar ações como "leia mais", "clique aqui", "atenção" melhorando a interatividade do site, substituindo por símbolos os quais os usuários já estão educados simbolicamente na web, como por exemplo setas para baixo indicando mais informações ocultas, setas para a direita com o objetivo de indicar para prosseguir, ponto de exclamação destacado demonstrando atenção, links e buscas de cores diferentes para que seja notório em meio ao texto e para que sejam encontrados com maior facilidade em um rápido acesso ao site. 
Os demais aspectos foram melhorados a partir de percepções nas demandas do usuário, os quais passaram a serem mais exigentes e estarem com o poder de consumo na mão, pois na web existem milhares de sites que oferecem o mesmo serviço, portanto a usabilidade não tem hora mais importante do que agora.

\section{RESULTADOS E DISCUSSÃO}

Para o desenvolvimento da reestruturação do layout, adotou-se alguns conceitos da web 2.0 associado a pesquisa de usabilidade. Buscou-se coletar opiniões a fim de alinhar informações para a criação de uma inteligência coletiva.

Além disso, estruturou-se o layout de forma que o design fosse aplicado e também facilitasse a usabilidade da página. Neste caso, iniciou-se pela alteração do campo de login no InfoHab, que estava com problema de visibilidade e mal posicionado. Pensando nisso, foi estabelecido na estratégia de design que seria reposicionado para conter melhor destaque. Login e cadastre-se foram posicionados no canto superior direito pois o internauta já está acostumado a procurar por essa ferramenta nesta posição, a opção "Entrar" foi substituída por uma seta para o lado direito que na web, universalmente sugere "Seguir", já a opção "Criar conta" estava muito pequena e escondida, então passamos ela ao lado do Login, aumentamos seu tamanho dando maior destaque e facilidade ao ser encontrada e acessada, passando a ter apenas um clique no processo.

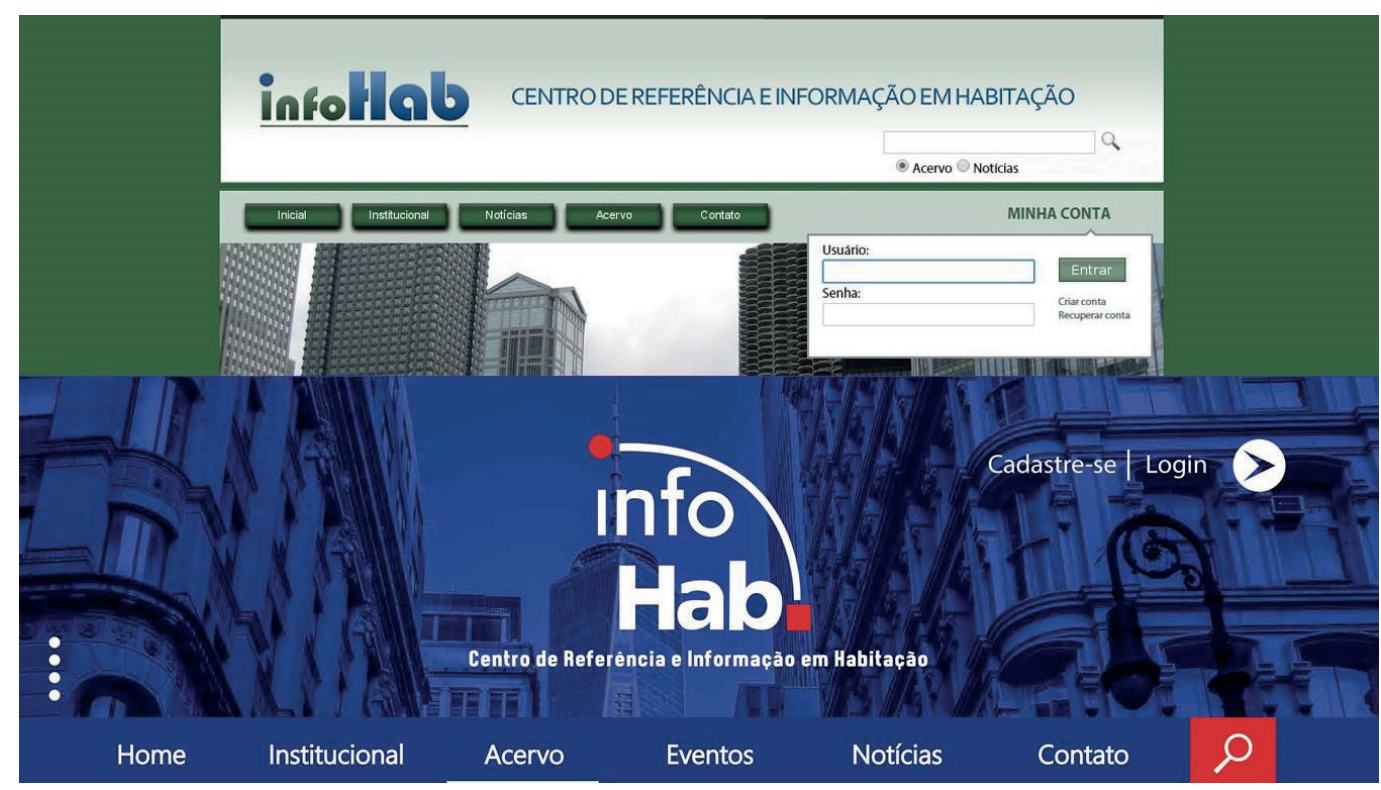

Figura 1 - Antes e depois das ferramentas de cadastro e login. Fonte: elaborado pelo autor. 
A ferramenta de busca foi aperfeiçoada, além de ter a opção no canto superior direito da tela em todas as páginas, foi criada a busca avançada dando opções de título, autor, evento, periódico, palavra-chave, período, tipo de documento e como aparecer ordenado o resultado da busca.

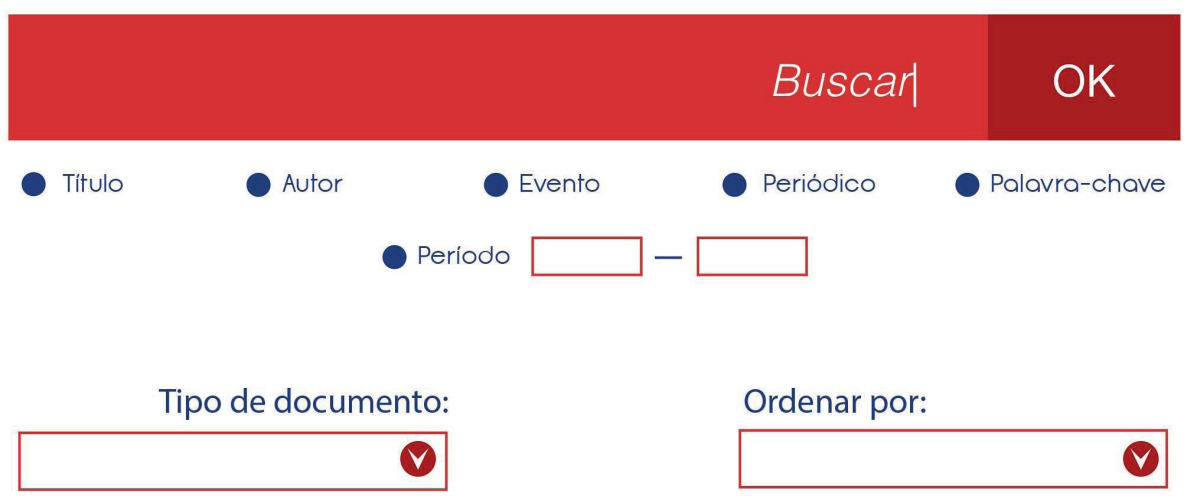

Figura 2 - Busca avançada. Fonte: elaborado pelo autor.

A identidade visual do InfoHab passou a utilizar a tela com a proporção real, retirando as tarjas laterais. No site antigo, as informações pareciam unidas, não tinha diferença em cores, tamanho de tipografia, ou texto para chamada. Com a reestruturação, passou a utilizar cores diferenciando informações qualitativas e quantitativas, mudança no tamanho de tipografia para texto de chamada e de descrição de conteúdo, utilização de fotos em um formato redondo para melhor enquadramento de imagens sem distorção. Tipografia no menu de ferramentas alterada para melhor legibilidade. Neste caso, teve-se como objetivo utilizar os conceitos da experiência do usuário na web, com o intuito de proporcionar uma navegação agradável e coerente, uma vez que pretendeu-se atingir o que o internauta busca quando está acessando uma página, focando em manter a sua permanência e interatividade com os conteúdos. 

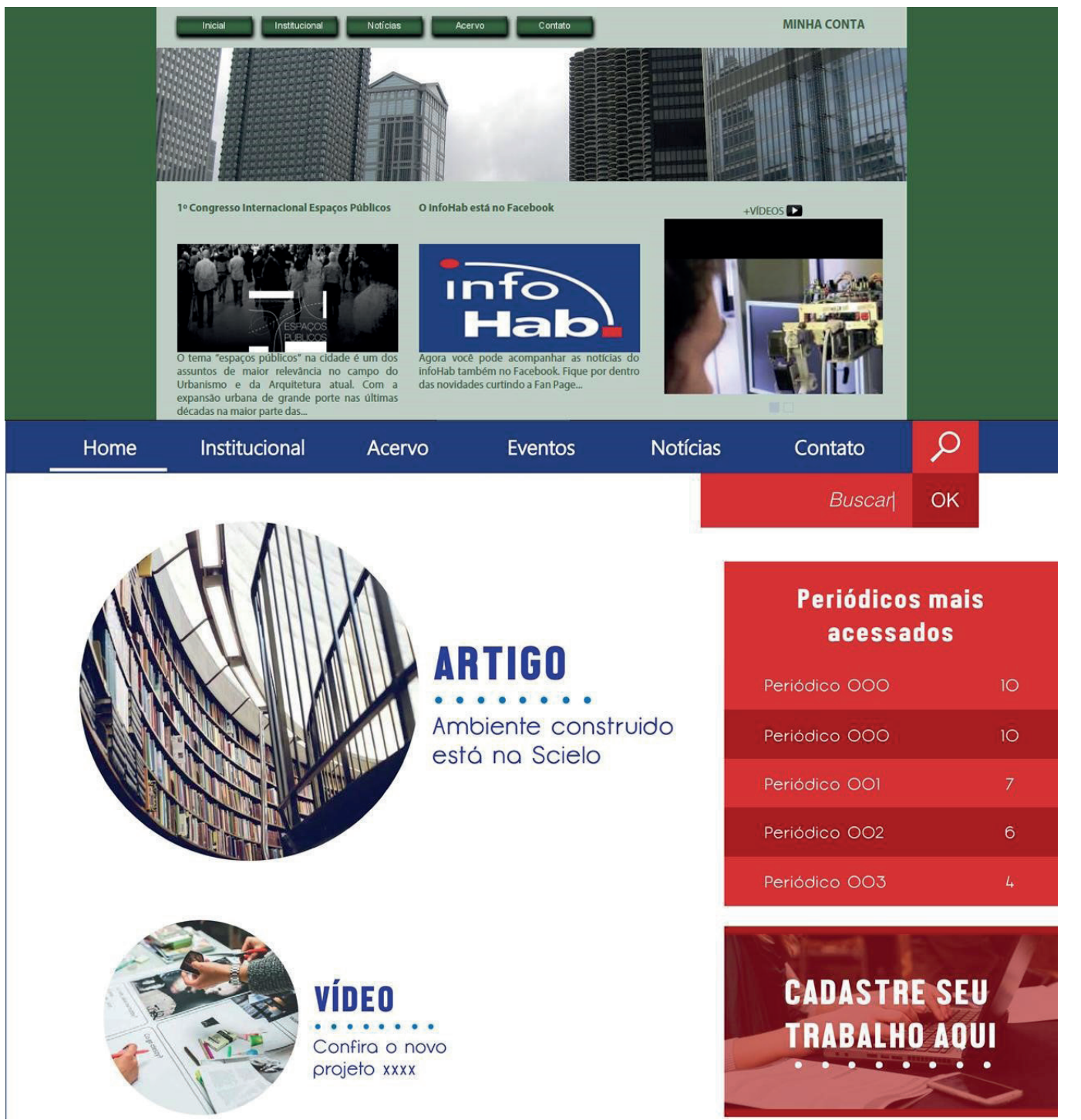

Figura 3 - Antes e depois da home. Fonte: elaborado pelo autor.

Foram adicionadas as opções de "Favoritos" para armazenar os documentos mais relevantes, perfil "Sobre o autor" mostrando o total de publicações, citações, índice-h, áreas e co-autores, resumo e abstract. A organização de trabaIhos cadastrados e de dados do perfil foram estruturados para melhor acomodação e legibilidade dentro da página, diferenciando cada categoria. 


\section{Perfil}

NOME COMPLETO

PROFISSÃO E INSTITUIÇÃO

Emoildempreso.com

Curriculo lottes

Nome em citaçōes bibliográficas

COMPLETO. N COMPLETO. NOME: COMPLETO. N A:

Editar dados

Meus trabalhos

$\square$ Adicionar Editar Excluir Citado por Ano

$\square \quad$ NOME DO PROJETO

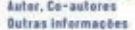

Nome

$20 \times x$

Indices de citoçōes

Citoçoes $\quad x x$ total I $x x$ Desce zoxi

Indice $\mathrm{h} \quad \mathrm{XX}$ totat I XX Desce 20xx

\section{Favoritos}

\section{$\square \quad$ Remover}

NOME DO PROJETO

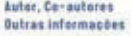

\section{Sobre o autor}

Crique no nome do[s] outor[es] paro ver o curriculo Lottes

\section{Cláudio Alcides Jacoski}

Documentos: 61

Citoçōes: 82 total de citaçōes em XX documentos

Indice $\mathrm{h}: 40$

Co-autores: 4

Áreas: Construço̊o civil. .

\section{Resumo}

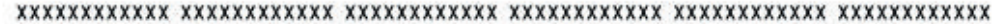

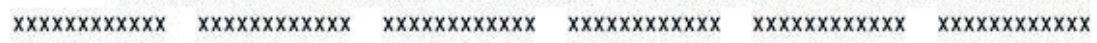

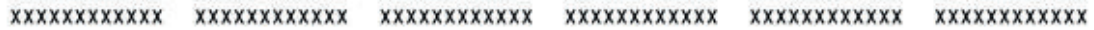




\title{
Abstract
}

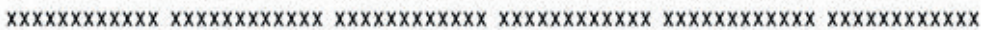

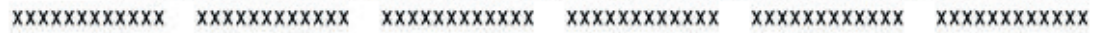

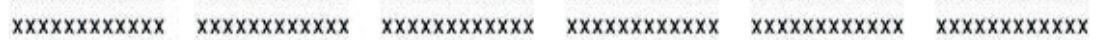

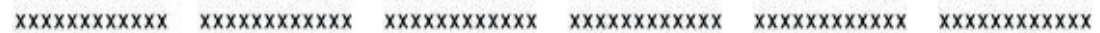

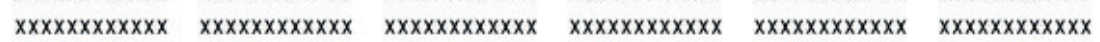

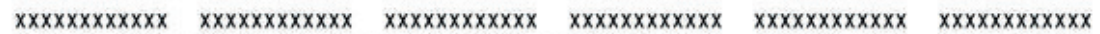

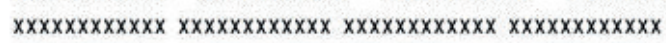

Figura 4 - Novo perfil e sobre o autor. Fonte: elaborado pelo autor.

Foi utilizado a rede social Facebook para divulgação do novo acervo e a projeção de conteúdos relevantes se aproximando do público, impulsionando também futuros eventos, publicações de artigos, curiosidades das novas ferramentas do site. Esta possibilidade, proporcionada principalmente pela internet 2.0 traz uma melhor oferta de conteúdos, potencializando a troca de informações, a fim de que sejam utilizadas ferramentas mais interativas na experiência tecnológica do usuário.
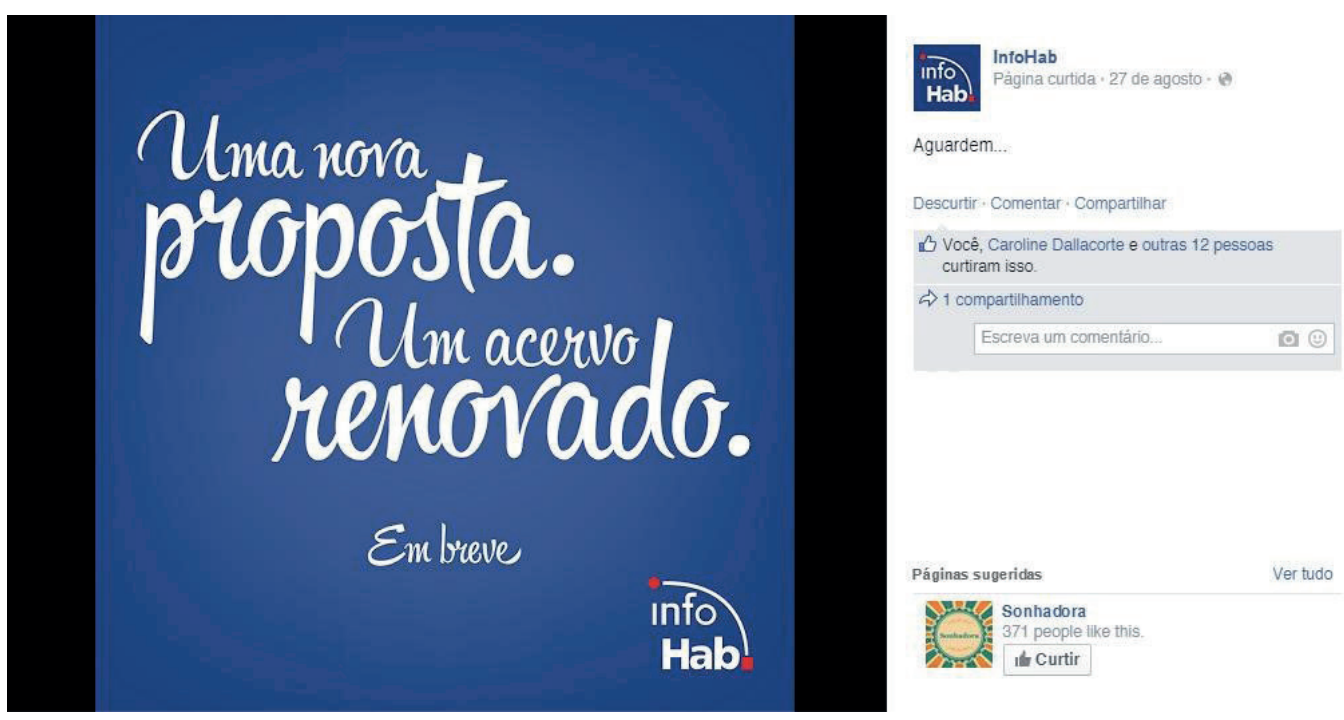

Figura 5 - InfoHab no Facebook. Fonte: elaborado pelo autor.

\section{CONSIDERAÇÕES FINAIS}

Menos é mais, pode-se resumir assim a maneira mais eficiente para um webdesign. As formas mais simples e mais limpas são as mais efetivas, desde a sua URL sendo nomeada de forma lógica e simples até a sua diagramação, opção de cores para ser recordado, e o design pesado faz com que se desvie a atenção 
de alguns pontos importantes que podem ser relevantes. A coerência visual trata-se de uma harmonização entre todos os aspectos presentes, que todos os elementos se completem e tornem um mesmo conceito visual. Deve ser tratado como um ambiente físico onde todos esses elementos juntos se completam e formam o conceito visual, passando sensações agradáveis.

No que diz respeito ao website os elementos de tipografia, linhas, cores, pictogramas, devem interagir como se fossem um só, mas isso não impede que um elemento cause um desconforto visual ao internauta, porém só é funcional quando ele tem um objetivo de causar esse impacto. Sendo assim, a alteração e cuidado com estes aspectos é fundamental, visto que este trabalho pode garantir, ou não, a permanência dos usuários na sua página e no acesso ao seu conteúdo.

O Webdesigner tem toda a liberdade de criar novos estilos e enfatizar elementos da melhor forma que puder, e isso é o diferencial do bom profissional. Não adianta o site ser fácil de mexer, estar cheio de conteúdos relevantes, se a identidade visual dele não ser agradável e se a diagramação das informações não estarem estruturadas de fácil leitura, já que com o perfil exigente dos usuários atuais, só se terá a sua confiança caso a interface da página o agradar e favorecê-lo a continuar sua busca de conteúdo, pois somente as informações não conquistam um internauta.

\section{REFERÊNCIAS}

ASSUNÇÃO, Renato Vieira da. Biblioteca digital: uma abordagem conceitual. In: ENCONTRO REGIONAL DE ESTUDANTES DE BIBLIOTECONOMIA, DOCUMENTA- ÇÃO, CIÊNCIA DA INFORMAÇÃO E GESTÃO DA INFORMAÇÃO, 14., 2011, São Luís. Anais... São Luís: UFMA, 2011. p. 1 - 13. Disponível em: <http://rabci. org/rabci/sites/defau It/files/BIBLIOTECA DIGITAL uma abordagem conceitual. pdf>. Acesso em: 24 nov. 2015.

DAMASCENO, Anielle. Webdesign: Teoria e Prática. Florianópolis: Visual Books, 2003.492p.

DE MOURA, Elton Alisson. A expansão das bibliotecas digitais e virtuais. FAPESP, 2015. Disponível em: <http://agencia.fapesp.br/a_expansao_das_bibliotecas_digitais_e_virtuais/21 753/>. Acesso em: 24 nov. 2015.

LORANGER, Hoa. Usabilidade na web: projetando websites com qualidade. Rio de Janeiro: Elsevier, 2007. 406p. 
MEMÓRIA, Felipe. Design para a Internet: projetando a experiência perfeita. Rio de Janeiro: Elsevier, 2005.

PREECE, Jennifer; ROGERS, Yvonne; SHARP, Helen. Design de interação: além da interação homem-computador. Porto Alegre: Bookman, 2005. 
Antônio Eduardo Rech Mota, estudante de Publicidade e Propaganda - Universidade Comunitária da Região de Chapecó, Área de Ciências Sociais Aplicadas Universidade Comunitária da Região de Chapecó, atuou como pesquisador de iniciação científica na Unochapecó desenvolvendo o design visual e layout da plataforma InfoHab e atualmente trabalha como estagiário na Acin - Agência de Comunicação Integrada da Universidade Comunitária da Região de Chapecó.

Caroline Dallacorte, Engenheira de alimentos, Programa de Pós-Graduação em Tecnologia e Gestão da Inovação - Universidade Comunitária da Região de Chapecó, sócia da startup PackID Soluções em Tecnologia, contemplada no Programa Sinapse da Inovação - Operação SC V com o projeto "embalagem inteligente: identifica temperatura por biossensor e RFID" e vencedora da competição de startups AdMaCom Berlim. Atuou como pesquisadora na modalidade de Desenvolvimento Tecnológico e Industrial na instituição Unochapecó. Possui graduação em Engenharia de Alimentos pela Universidade Comunitária da Região de Chapecó Unochapecó. Realizou mobilidade acadêmica na Universitat Rovira i Virgili (Espanha) onde atuou como pesquisadora voluntária na área de microbiologia. Possui experiência como pesquisadora nas áreas de análise sensorial e desenvolvimento de novos produtos, inovação tecnológica, embalagens inteligentes, clusters e desenvolvimento regional.

Claudio Alcides Jacoski, Doutor em Engenharia de Produção - Universidade Federal de Santa Catarina, Programa de Pós-Graduação em Tecnologia e Gestão da Inovação - Universidade Comunitária da Região de Chapecó, Mestre em Cadastro Técnico Multifinalitário, Especialista em Gestão e Liderança Universitária, Engenheiro Civil, foi coordenador de curso de Engenharia Civil, Presidente do Conselho Editorial da Editora Argos, Diretor do Centro Tecnológico da Unochapecó, foi Vice-Reitor de Pesquisa, Extensão e Pós Graduação, Vice Reitor de Planejamento e Desenvolvimento. Vice-Presidente da SAC - Sociedade Amigos de Chapecó, membro do Conselho de Desenvolvimento Econômico e do Conselho de Tecnologia e Inovação do Município de Chapecó. Possui mais de uma centena de artigos publicados em Revistas e eventos em diversos países. Recebeu prêmios internacionais como o da RED CYTED e do Caderno de competências empreendedoras de Engenharia da Rede PRECITYE da América Latina. Coordenou projetos de pesquisa, entre eles: GVIP, INFOHAB+10, e coordena o projeto do 1o Museu de Ciência e Tecnologia do Oeste Catarinense. Pesquisa temas como Gestão da Inovação, TIC na Construção, e BIM, é responsável pelo 
INFOHAB - Centro de Referência e Informação da habitação. Foi idealizador da Rede de Inovação e coordenou as atividades do Parque Científico e Tecnológico Chapecó@.É professor do Programa de Pós-Graduação em Tecnologia e Gestão da Inovação e do Programa de Pós Graduação em Contabilidade e Administração da Unochapecó, foi também docente do Programa de Pós Graduação em Ciências Ambientais. Coordenou o Grupo Temático de Universidades Empreendedoras da International Triple Helix.

Recebido em: 16/03/2017

Aceito em: 10/04/2017 